Goldschmidt 2021 Abstract

https://doi.org/10.7185/gold2021.3875

\section{Exploring hydrodynamic controls on organic-rich sediments under oxygen- deficient marine settings}

\author{
ELENA TARIRO BRUNI ${ }^{1}$, THOMAS MICHAEL \\ BLATTMANN $^{2}$, NEGAR HAGHIPOUR ${ }^{1}$ AND TIMOTHY \\ IAN EGLINTON $^{1}$
}

${ }^{1}$ ETH Zurich

${ }^{2}$ Japan Agency for Marine-Earth Science and Technology (JAMSTEC)

Presenting Author: elena.bruni@erdw.ethz.ch

The preservation of organic matter in marine settings varies with oxygen exposure time as well as the origin, type, and composition of organic matter, microbial community structure, and many more factors. In contrast to oxic systems, sediments deposited under oxygen-deficient conditions are enriched in organic matter-replete low-density macroaggregates. Their accumulation results in increased proportions of coarse-grained low-density particles relative to mineral-associated organic matter that predominates in sediments underlying oxygenated water columns [1]. However, the hydrodynamic properties and the fate of these low-density organic matter-laden sedimentary particles remain mostly unexplored.

To examine the hydrodynamic characteristics of OM-rich sediments, we analyzed geochemical and sedimentological properties of surficial sediment samples from eastern boundary upwelling systems and oxygen minimum zones. We find large variations in TOC, $14 \mathrm{C}$ age, and organic matter-molecular composition as a function of location, grain size, and density (Fig. 1). For example, offshore Namibia, absolute values of Fm and TOC decrease with distance to the shore, while variance between the fractions increases. Our results indicate that organic matter-replete surface sediments enriched in low-density particles are especially prone to resuspension. Consequently, the high abundance of low-density sedimentary particles accumulating under low oxygen conditions implies a high propensity for hydrodynamic sorting, and hence, lateral dispersal and redistribution. These findings have significant implications for our perception of sediment and organic matter-accumulation under oxygen-deficient water columns that have been prevalent during key periods of earth history [2].

Figure 1: Fraction modern ( \pm abs. error) of surface sediments taken from 2 transects offshore Namibia, shown as density (left) and grain size fractions (right). Sediments further offshore are characterized by lower TOC and more aged organic matter. The youngest ages are found in the organic matter-rich 1.6-2.0 g cm3 density fractions, with no such relationship evident from grain size fractions.

[1] Arnarson, T. S. \& Keil, R. G. Organic-mineral interactions in marine sediments studied using density fractionation and $\mathrm{X}$ ray photoelectron spectroscopy. Org. Geochem. 32, 1401-1415 (2001).

[2] Ausin, B. et al. (In)coherent multiproxy signals in marine sediments: Implications for high-resolution paleoclimate reconstructions. Earth Planet. Sci. Lett. 515, 38-46 (2018).

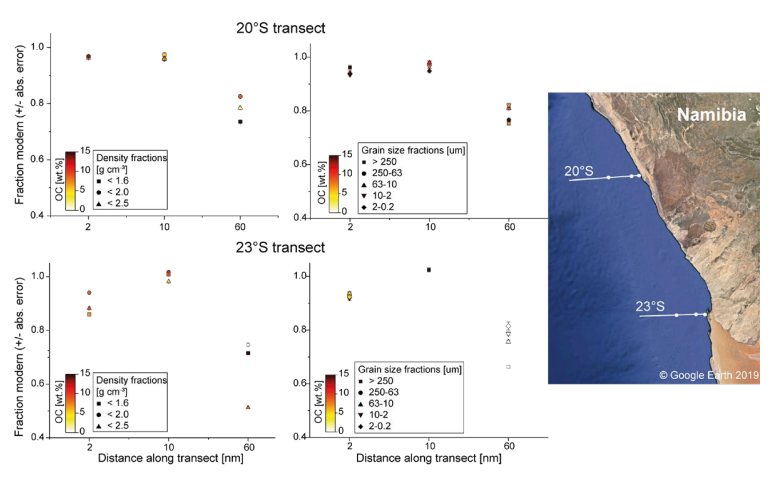

